\title{
La formación del predicador: de la Rhetorica Christiana de Fray Diego Valadés a Antonio Margil de Jesús
}

\author{
Preacher training: From the Rhetorica Cristiana by Fray Diego Valadés to \\ Antonio Margil de Jesús
}

Esteban López Arguedas*

\begin{abstract}
RESUMEN
El presente artículo desea demostrar cómo el modelo de predicador propuesto por Fr. Diego Valadés en su Rhetorica Cristiana en 1579 continúa vigente en la formación discursiva de El peregrino septentrional atlante. Delineado en el exemplarissima vida del venerable padre F. Antonio Margil de Jesús de Fr. Isidro Félix de Espinosa, en 1737.

La Rhetorica Cristiana nace de las resoluciones contrarreformistas del Concilio de Trento y pretende, no solo exponer las normas y reglas que debe seguir el orador sagrado, sino también un acervo de conocimientos útiles tomados de las Sagradas Escrituras, los Padres de la Iglesia, las ciencias paganas y la teología cristiana.

Por su parte, en su obra, Espinosa alcanza el ideal de escritura prescrito por la Rhetorica Christiana al crear una hagiografía que es a la vez: la consecución del predicador santo en la figura de Margil por sus conversiones entre tribus rebeldes y criollos réprobos; y un ejemplo de la estilística de las letras del Barroco novohispano.
\end{abstract}

Palabras claves: Barroco, retórica novohispana, hagiografía, predicadores del Nuevo Mundo, Propaganda Fide.

\begin{abstract}
This article intends to show how the model of the preacher proposed by Fr. Diego Valadés in his Rhetorica Cristiana in 1579 is still valid on the discursive formation of El peregrino septentrional atlante. Delineado en el exemplarissima vida del venerable padre F. Antonio Margil de Jesús by Fr. Isidro Félix de Espinosa in 1737.

Rhetorica Cristiana has its origins at the counter-reforming decisions from the Council of Trent and intend not only to expose the rules to be followed by sacred speakers, but to propose a core of useful knowledge taken from Holy Scriptures, Early Church Fathers, Pagan Sciences and Christian Theology.

In the other hand, Espinosa in his work reaches the ideal writing prescribed by Rhetorica Christiana creating a hagiography that is at the same time, the attain of the holy speaker in the figure of Margil because of the conversion of rebel tribes and damned criollos, and an example of the stylistic of the New Spain Baroque letters.
\end{abstract}

Key words: Baroque, new Spain rhetoric, hagiography, New World preachers, Propaganda Fide.

\footnotetext{
* Universidad de Costa Rica. Bachiller en Filología Española y estudiante de la Maestría Académica en Literatura Latinoamericana. Correo electrónico: esteban7lopez@gmail.com
}

Recepción: 12/09/2018.

Aceptación: 6/02/2019. 


\section{Introducción}

El presente artículo demuestra la vigencia del modelo discursivo expuesto por Fr. Diego Valadés en su Rhetorica Christiana, escrito en el año 1579, en la conformación escritural de El peregrino septentrional atlante. Delineado en la exemplarissima vida del venerable padre F. Antonio Margil de Jesús de Fr. Isidro Félix de Espinosa, en 1737.

La Rhetorica Christiana es un documento de carácter preceptivo y etnológico. En su aspecto preceptivo no solo se limita a la exposición de las formas retóricas y sus usos dentro del sermón para lograr conversiones, sino que también es preceptivo en la intención de hacer del orador cristiano un vivo ejemplo del contenido de sus sermones, una imitatio christi. En su obra, Valadés forja el ideal del misionero santo novohispano.

El carácter etnológico de la obra, como se verá más adelante, es lo que principalmente la diferencia de otros documentos similares y contemporáneos, como la Ecclesiasticae Rhetoricae de Fr. Luis de Granada, con la cual se le ha comparado. La obra de Granada, publicada un año antes, fue conocida por Valadés. Al respecto, Vernier (2001) comenta:

Nada tendría de raro que el franciscano se hubiera inspirado en la obra del español, porque en lo que a retórica en general se refiere y en particular a la eclesiástica, la originalidad hacía mucho que había desaparecido y eran normales- justificables incluso- la copia y la repetición (p. 440).

Valadés, hijo de una indígena tlaxcalteca y del conquistador Diego Valadés, tuvo la oportunidad de educarse en el Colegio de la Santa Cruz de Tlatelolco, bajo la tutela de Pedro de Gante y Bernardino de Sahagún. Se puede suponer que Valadés estudió a los 
autores clásicos y del Renacimiento, porque en el índice de la biblioteca de Tlatelolco se encontraban las obras de los más famosos humanistas: Erasmo de Rotterdam, Juan Luis Vives y Antonio de Nebrija. También, se sabe que tenía a su haber De oratote de Cicerón y la Institutio oratoria de Quintiliano, así como los clásicos greco-latinos Aristóteles, Platón, Marcial, Juvenal, Virgilio, Tito Livio, entre otros. El Colegio de la Santa Cruz de Tlatelolco mantuvo el mismo programa didáctico que los centros de estudio renacentistas europeos, basados en la enseñanza de la gramática, lógica, retórica, filosofía y música. Además, los alumnos recibían lecciones de la medicina natural mexica y de las lenguas autóctonas de las comunidades indígenas.

Se tiene conocimiento de que Valadés después estudió el otomí, el tarasco y el náhuatl durante sus años de misión en las zonas de Durango, Querétaro y Zacatecas. Esta experiencia misional, así como su origen mestizo, son probablemente la fuente de su visión etnográfica. Antes de la publicación de su obra, se decanta (presionado por sus superiores), por el título de Rhetorica Christiana, para enfatizar en el carácter didáctico de la obra, cuya inspiración nace directamente de las resoluciones del Concilio de Trento y se utilizaría como instrumento pedagógico en la formación de los futuros misioneros (especialmente entre los franciscanos) en el Nuevo Mundo. No obstante, Valadés pensó en un principio en el título Suma de todas las ciencias más excelsas, por contener en realidad un resumen sistemático o compendio de ellas, como arsenal necesario para el orador sagrado, el cual debe echar mano de todos los conocimientos.

En 1564, Felipe II, mediante cédula real, manda poner en práctica en Nueva España las resoluciones del Concilio de Trento, confirmado por Pío IV con la bula Benedictus Deus. Entre los intereses fundamentales del concilio, se encontraba crear un modelo nuevo 
de religioso. Por esa razón, el concilio ordenaba la fundación de seminarios para la formación intelectual de los postulantes. Este nuevo prototipo de religioso era la reivindicación del sacerdote de conductas laxas y vida licenciosa que tanto criticaba Lutero. El modelo tridentino de sacerdote se toma seriamente el cumplimiento de los votos de pobreza, obediencia y castidad. A la luz de las resoluciones tridentinas, las órdenes mendicantes hicieron una reestructuración de su regla y volvieron a las disciplinas de sus padres fundadores. En la orden de San Francisco, los frailes menores fueron quienes asumieron la tarea de reformar la orden. Otra de las conclusiones tridentinas atinentes a la escritura de la Rhetorica Christiana es aquella que declara que los fundamentos de la fe son las Sagradas Escrituras, en conjunto con la tradición de la Iglesia, las enseñanzas recibidas por los apóstoles por medio oral, y conservadas a través de los siglos en los textos de los Padres Apostólicos, de los Padres del Desierto y de los Padres de la Iglesia, la sucesión petrina ininterrumpida del Primado de Roma y los Concilios.

De esta manera, en 1579, Fr. Diego Valadés publica su Rhetorica Christiana con una finalidad humanista eminentemente práctica: formar buenos predicadores de la divina palabra, que conocieran a fondo el arte de la elocuencia cristiana y estuvieran bien pertrechados de los conocimientos de las ciencias divinas y humanas. Esta obra fue escrita originalmente en latín, constituida por seis libros que exponen de manera sistemática los principios, fines y recursos de la teoría oratoria. Se describirá brevemente el contenido de cada uno de los libros para luego enfocarse en los tres ejes temáticos que sirven de vasos comunicantes entre los dos autores:

- Libro I (dieciséis capítulos): Propone un arsenal tomado de las reglas y enseñanzas que contiene la Sagrada Escritura. En este libro, también, se definen las 
cualidades del orador cristiano, qué calidades deben resplandecer en el sacerdote digno y cuáles son los fines que debe proponerse el predicador.

- Libro II (treinta capítulos): Define la retórica, sus divisiones y partes. Además, este contiene una ingeniosa recapitulación mnemotécnica de todos los libros de la Biblia.

- $\quad$ Libro III (veintiún capítulos): Muestra cómo en los libros sagrados y en su interpretación, se encierra un valioso tesoro para infundir vida a los sermones. Trata también de la importancia que tiene en la oratoria la pronunciación y saber mover los afectos.

- Libro IV (veinticinco capítulos): Expone cuáles son los géneros de las causas y cuál es el oficio del orador. Asimismo, refiere la variedad y multitud de dioses entre los indios, sus ritos y todo lo que entre ellos es digno de mención en aquella nueva parte del orbe.

- Libro V (once capítulos): Explica cuáles son las partes que integran el discurso y cómo se lleva a cabo la composición de este.

- Libro VI (veintiún capítulos): Habla sumariamente de las figuras y adornos de la retórica.

Del extenso volumen de saberes que contiene la Rhetorica, se han extraído tres ejes temáticos presentes en la formación discursiva de El peregrino septentrional atlante: la formación del misionero, la preceptiva retórico-literaria de la composición del sermón y otros textos, y el componente antropológico-etnográfico en la visión y comprensión del mundo del 'otro' indígena. 


\section{La formación tridentina del misionero, la edad dorada de la evangelización en Nueva España}

Ante las severas y justas críticas que hizo Lutero contra los obispos y sacerdotes disolutos, abusadores de su grey y hasta heréticos en la administración de los sacramentos, el Concilio de Trento busca una mayor moralización del clero. Fr. Diego Valadés, acogido en este precepto e inspirado por la generación de misioneros inmediatamente anterior, incluye en su Rhetorica una especie de "breviario hagiográfico" para que el misionero logre, a través de él, alcanzar la elocuencia iluminada, que sería en realidad muy poco en comparación con el ideal mayor: la perfección del espíritu a partir del depuramiento personal por la perfecta vida religiosa. No obstante, Valadés (2003) no permite que la natural codicia, aunque sea la santidad lo que se anhele, confunda al fraile y recuerda constantemente el sic transit gloria mundi:

Y así, el orador cristiano no debe buscar su propia gloria, sino la de Jesucristo a quién debe desear tener siempre ante sus ojos, y buscar la edificación de su cuerpo místico que es la Iglesia unánimemente católica. No la suya, decía, porque no debe hacer nada que no se encamine a la gloria del solo Dios (p. 59).

El concepto de retórica que fundamenta al orador ideal en la obra de Valadés no es el de Aristóteles, quien la considera el arte de encontrar en cada materia los medios para persuadir; sino la que ofrece Quintiliano como bene dicendi scientia. Esta definición añade a la elocuencia un modo de vida, en donde el buen orador es también un hombre bueno que se alimenta de la sabiduría. Este ideal de misionero tendría la ingente labor de convertir mediante la prédica a los naturales de todos los confines de Nueva España. 
En su Libro I, Valadés personifica con ejemplos y pormenores la exacta imagen del predicador como hombre bueno, de la cual se mencionan las siguientes características:

- $\quad$ Citius, altius, fortius: El atleta de Cristo. Este es de apariencia pulcra, situado entre las criaturas más altas, aventaja a los demás por la nobleza de sus costumbres y su bondad: pulcro en la conversación, claro en el discernimiento y más alto y elevado en la contemplación.

- $\quad$ Obsequiosidad angélica: Presencia invisible de un ángel pedagogo y pastor; muestra las cosas ocultas y revela cosas secretas.

- Desprecia el mundo y su concupiscencia.

- $\quad$ Espejo, no oculta nada y muestra la imagen de Cristo.

- $\quad$ Físicamente fuerte, resistente a las arduas jornadas y no le teme a los tormentos; se mantiene fuerte y resistente.

- Diligentes en labores eclesiásticas.

- $\quad$ Agradables en el discurso.

El ideal de predicador está moldeado en las Sagradas Escrituras, principalmente en las figuras de Daniel, San Pablo y Jesús. Fr. Diego se extiende en la recolección de epítetos que el mismo texto bíblico atribuye a la labor de llevar la buena nueva, como: "luz del mundo", "sal de la tierra" y "pastor de las almas". Esta buena nueva, según se desprendía de las ordenanzas tridentinas, incluía también la buena donación de los sacramentos y, de entre ellos, con mayor importancia, el bautismo. Este era el instrumento de fe más poderoso en la batalla contra el diablo, pues con él los indígenas adquirían su condición de cristianos e hijos de Dios. Pero, para otorgarles el bautismo y acrecentar el reino de Dios, primero 
debían persuadirlos de abandonar sus idolatrías y supersticiones para aceptar la verdad católica y vivir piadosamente. Vernier (2001) afirma que:

Esta descripción contiene un programa de trabajo, el que tuvo en la conversión, mediante la prédica, para enseñar a los mexicanos del siglo XVI a vivir con inocencia, sin supersticiones, ni malas costumbres; es otra manera de cristianismo primitivo, que se impuso, dentro de términos históricos, en breve tiempo, mediante otra forma de sermo humilis descrito con pormenor e ilustrado con lujo, en la parte cuarta de esta retórica (p. 440).

Este cristianismo primitivo que menciona Vernier, lo encarnan las primeras generaciones de misioneros en Nueva España durante el siglo XVI. Antonio Rubial García se refiere a este periodo como la edad dorada de la evangelización. Este proyecto evangelizador, como señala Vernier (y el mismo Valadés), se impuso en breve tiempo, significó trabajos extenuantes para los misioneros que avanzaban a pie desde Jalisco y la Huasteca hasta Guatemala; a través de regiones inhóspitas y entre mosquitos y alimañas. Esta visión idílica de la primera Iglesia indiana donde todo era perfecto fue creada principalmente por Jerónimo de Mendieta, otro franciscano, en su Historia eclesiástica indiana. Fr. Diego moldea su ideal de predicador inspirado en las referencias de misioneros, como Mendieta, que lograban muchas conversiones pese a la constante oposición de Satanás. Los frailes debían enfrentar los obstáculos más graves que los curanderos y los indios apóstatas les oponían para frenar el avance de la misión. El mismo Valadés experimentó la vivencia misional durante el tiempo que pasó entre los chichimecas. 
Llama la atención que este sermo humilis (forma retórica para predicar a las personas más sencillas), al que también se refiere Vernier, implicaba que el fraile se preparara académicamente, pues el complemento del hombre bueno era el hombre sabio. Para la formación de este misionero ideal, Valadés recomendaba la instrucción basada en el modelo renacentista del Trivium y Cuadrivium. De esta forma, aconseja el estudio de las siguientes disciplinas: gramática como la llave y madre de las otras artes, retórica que es ornamento de las ciencias, dialéctica que previene la agudeza de las palabras, los proverbios y las palabras de los sabios y sus enigmas, matemáticas que demuestra las cantidades continuas y discretas, y la metafísica, la aritmética y la geometría.

El autor de la Rhetorica indica que para evitar que el fraile caiga en la soberbia intelectual propia del filósofo pagano, quien sabe muchas cosas pero cuya fuente de conocimiento sigue siendo el mundo natural y sus fenómenos, por tanto solo se atiende a la vida presente, debe entronizarse como madre y conductora del entendimiento a la teología, que es la más importante de todas las ciencias. Las ciencias de los filósofos deben ser aprehendidas a través del crisol de la teología, para que en todas ellas Dios sea buscado, conocido y amado.

\section{La preceptiva retórico- literaria de la composición del sermón y otros textos}

En la composición de este sermo humilis, el autor se inspira en el Eclesiastés, que dice: sapiens in verbis seipsum amabilis reddit. Sería largo y tedioso referirse a los usos y formas retóricas que el texto contiene; sin embargo, vale la pena rescatar el tratamiento que 
le da Valadés a las cinco divisiones clásicas de la oratoria: inventio, dispositio, elocutio, memoria y actio.

El estudio de esta preceptiva literaria, vista aquí a grandes rasgos, debía procurarle al orador un catálogo de recursos estilísticos, exegéticos y doctrinales; así como un corpus de citas y pasajes de las Sagradas Escrituras y de autores paganos, para la elaboración de sus sermones. Valadés ofrece ejemplos de sermones ya escritos y recomienda a aquellos misioneros cuya destreza en las letras es mínima, pero compensada por un gran fervor misional, memorizarlos tal cuales y repetirlos en los días de las festividades.

Gran cantidad de cronistas del Nuevo Mundo fueron quienes en esta edad dorada de la evangelización escribieron las crónicas de sus misiones, menologios, martirologios e incluso planes de estudio con este modelo retórico renacentista, como se verá pronto en la formación discursiva de El peregrino septentrional atlante.

\section{Componente antropológico-etnográfico en la visión y comprensión del mundo del "otro" indígena}

El tercer eje temático, se refiere al interés etnológico que demuestra Valadés al describir e interpretar algunos aspectos de la cultura del indígena. Este interés no era nuevo entre los frailes menores, basta recordar la extensa recopilación oral que hace Fr. Bernardino de Sahagún sobre todos los aspectos de la cultura azteca, los cuales recogió y explicó en su Historia General de las cosas de Nueva España.

Este elemento etnográfico también diferencia la obra de Valadés de las otras retóricas cristianas escritas en la misma época. Para lograr introducir esta visión en una obra de naturaleza retórico-preceptiva, Valadés se apoya en una de las herramientas que la 
misma retórica le ofrece: el uso del exemplum. Quintiliano se refiere a su uso como "traer un hecho sucedido o cómo sucedió, útil para probar lo que queremos". Así, Valadés, en lugar de recurrir en este aparte a las formas clásicas, busca ejemplos basado en su propia experiencia de mestizo y, con ello, integra el Nuevo Mundo en su retórica. Carrasco (2000) señala al respecto lo siguiente:

A nuestro juicio, en la complejidad discursiva (preceptiva e iconográfica) de la Rhetorica Christiana confluyen diversas tradiciones que se integran en una específica visión del hombre americano y de la historia que, gracias a la utilización retórica del exemplum, pone en discusión ante sus destinatarios europeos no solo la supuesta inferioridad natural del indígena americano, sino también su integración en la cultura cristiana universal (p. 40).

Los ejemplos y observaciones del mundo indígena que Valadés utiliza para ilustrar sus sermones buscan, al mismo tiempo, legitimar y defender la incorporación del indígena en la unidad de la naturaleza humana. Desde los tiempos de Ubertino de Casale, la corriente milenarista entre los franciscanos rastreaba en la historia los signos del advenimiento de la parusía. La aparición de los habitantes de América en el panorama de la cristiandad tuvo su explicación, entre los franciscanos, como parte del plan divino. Con la llegada providencial de los trece primeros frailes a Nueva España, la descripción e inserción de esa "otredad" coincidía con la defensa del apostolado franciscano, como puerta de entrada de estos seres en la "historia de la salvación". De esta manera, la Rhetorica Christiana, de acuerdo con los postulados teológicos de Paulo III, legitima la capacidad racional del indígena, condición que le garantiza su acceso a la fe cristiana. 
La descripción que se hace de los indígenas, como es la tónica en los textos de sus contemporáneos y será la misma entre casi todos los cronistas de las órdenes religiosas durante el periodo colonial, está hecha a partir de una percepción binaria del indígena. Por un lado, se retrata como el "buen salvaje", un ser dócil que pareciera vivir aún en un pasado edénico anterior al Génesis, donde la comunidad vive verdaderamente el Evangelio, aunque nunca hayan oído hablar de él. En este caso, a través del género epidíctico, se elogia al indígena con el interés indirecto de resaltar la labor evangelizadora y la pertinencia de la empresa misional en el continente:

Esas trece lumbreras- los primeros que evangelizaron estas tierras- tuvieron como principal objetivo atraer aquellas bárbaras naciones, con el brillo de su vida y doctrina, al conocimiento de Dios y de nuestra Santa Madre Iglesia romana y de su cabeza y Vicario el Pontífice de Roma, y a la obediencia del rey... Acostumbran entre ellos [los indios] después de haber escuchado la instrucción catequística de la que ya se hizo mención, recitar todos a una, con grande atención, la confesión general. Una vez terminada esta, se les lee el modo de confesarse siguiendo por orden los Diez Mandamientos, lo escuchan con suma atención, y mientras están oyendo anotan por medio de granos de maíz o piedritas los pecados y su número, con sus circunstancias; o dibujan figuras o imágenes, y de este modo se confiesan bien, con claridad y facilidad (Valadés, 2003, p. 214).

Por otro lado, aparecen descritos como seres abyectos, imbuidos en la maldad, por haber hecho al diablo reino de estas tierras, hasta entonces ajenas a la luz de la verdad cristiana. Entre los tópicos recurrentes de las crónicas y sermonística colonial, tienen un lugar destacado la presencia y la acción del diablo. Antagonista de la fe verdadera y 
enemigo de Dios y sus hijos, este personaje, según interpretaron los frailes a partir de los ritos religiosos de los nativos, había hecho de estas tierras su reinado. Los sacerdotes de las tribus eran sus acólitos y sus formas religiosas fueron desacreditadas por considerarlas practicas adivinatorias, magia y superstición idólatra. Por supuesto, es en esta lucha campal contra el maligno, donde las fortalezas del misionero deben relucir y donde su retórica debe penetrar hasta el corazón de su auditorio para erradicar de ellos cualquier vestigio de herejía. Con este fin, muchas veces sus sermones iban acompañados de la destrucción pública de ídolos, como prueba del poder superior del dios cristiano. La lucha contra el demonio y sus huestes es uno de los temas más constantes en la mentalidad postridentina, y fue motivo de gran cantidad de obras pictóricas, musicales y literarias; entre ellas, los mares de páginas escritas referentes a la acción cristianizadora/civilizadora. Sobre este tema, Valadés (2003) indica que:

Entre los nefandos, horrendos y crueles crímenes de los indios, encontrábanse las artes mágicas, que enseñaban el modo de tener pacto y comunicación con los demonios, o para invocarlos, o también para hacerles sacrificios o para elevarles súplicas como a Dios, con el fin de venir en conocimiento de las cosas presentes o futuras, o de que se realicen algunos portentos, o para inferir algunos males. Por eso ponemos en la primera línea de este cuadro al mismo demonio y a aquellos que le ofrecen sacrificios, pues ellos por causa de sus obras y sacrificios se asemejan a él. Y porque el culto de todas estas cosas nefandas es la causa de todo mal y su principio y fin, por eso pintamos su cabeza coronada de serpientes y los brazos extendidos hacia lo malo y a él mismo sentado en esa forma (p. 218). 
Pasados los años, la Rhetorica Christiana continuó como modelo escritural para los cronistas religiosos de Nueva España.

\section{La formación discursiva del predicador, el caso de Fr. Antonio Margil de Jesús}

En 1682 se funda, en Querétaro, el Colegio de Propaganda Fide de la Santa Cruz, el primero de varios que se establecerían en el continente. Con la llegada de la Congregación de Propaganda Fide, los frailes menores reforzaron sus misiones que habían venido en decaimiento en ambos extremos de las fronteras de Nueva España. Por estos años, arriba a México Antonio Margil de Jesús, fraile de origen valenciano, de quien Rubial (1999) anota que:

Con él los franciscanos obtenían por fin al candidato ideal, no solo para hacerlo objeto de una abundante hagiografía y para proponerlo a Roma para su veneración universal, sino también para construir alrededor de él una segundad edad dorada. Fray Margil fue para la Nueva España del siglo XVIII el modelo más acabado del misionero (p. 259).

A continuación, se rastrearán en la formación discursiva del personaje de Antonio Margil de Jesús, los tres ejes temáticos planteados para la obra de Valadés.

\subsection{La segunda edad dorada: Las misiones en el norte y en el sur}

Los acelerados cambios sociales y económicos que atravesaba Nueva España en la segunda mitad del siglo XVIII y la situación interna de la orden franciscana, crearon las 
condiciones propicias para que naciera la idea de una edad dorada que se situaría en la etapa anterior. Sobre este asunto, Rubial (1999) menciona que:

Detrás de esta visión de una Iglesia Indiana casi perfecta estaba la necesidad de acabar con los abusos y con la explotación de los indios. Al hacer patente la labor misional de los religiosos se cuestionaba la nueva política que pretendía desplazarlos y suplantarlos por los seculares; al mostrar las ventajas que había tenido la separación entre indios y españoles se hacía evidente el perjuicio moral y físico que trajo consigo la convivencia; al exaltar las virtudes de los frailes ilustres de los primeros tiempos de la conquista espiritual, se confrontaban los vicios y la relajación que comenzaba a filtrarse entre las nuevas generaciones de religiosos (p. 258).

El impacto de esa edad dorada sobre los cronistas franciscanos, dominicos y agustinos fue enorme. Sobre sus premisas tridentinas, se escribieron todas las crónicas provinciales, que en realidad se dedicaron a repetir y reelaborar los materiales del siglo XVI. El peregrino septentrional atlante es un texto paradigmático en este tipo de escritura de la segunda edad dorada.

Antonio Margil de Jesús, fallecido en 1726 a los 79 años de edad, gozó de una extendida fama en toda Nueva España durante el siglo XVIII. Su trabajo misional abarcó todo el territorio del virreinato, desde Texas hasta Talamanca. Participó activamente en la fundación del primer Colegio de Propaganda Fide en Querétaro y fue el fundador de dos colegios más: el Colegio de Santa María de Guadalupe en Zacatecas, que atendía las misiones hacia el norte; y el Colegio de Cristo Crucificado en Antigua Guatemala, encargado de las misiones en Centroamérica. La fama de Margil creció aún más después 
de su muerte, a tal punto que se le abrió un proceso de beatificación, proceso que no llegó a un resultado en los altares, como sí sucedió recientemente en el caso de Fr. Junípero Serra, quien misionó en la zona de California y fue también miembro del Colegio de Santa María de Guadalupe en Zacatecas.

Nueve años después de su muerte, Fr. Isidro Félix de Espinosa publica la primera hagiografía formal del venerable padre, y algunos años después, Fr. Hermenegildo Vilaplana publica otra hagiografía en su honor. En la segunda mitad del siglo XVIII, se reaviva la crónica y la estilística que casi 160 años antes propuso Fr. Diego Valadés. Este reavivamiento que traen los misioneros de Propaganda Fide, se da en el momento en que las misiones franciscanas están perdiendo su lustre frente a los avances de los jesuitas en el norte de México. Los hagiógrafos seráficos, afirma Rubial (1999), encontraron una salida en otra de sus glorias pasadas: el lego Sebastián de Aparicio, cuya causa se llevaba en Roma. Empero, el siervo de Dios no había sido misionero y, por lo tanto, no podía cumplir con las expectativas de la orden, ni siquiera con las literarias.

Como se observará en los extractos del texto, Margil encarna las características del "hombre bueno" que describe la Rhetorica Christiana; en él se plasma tanto el ideal del sacerdote de la contrarreforma como el recuerdo de los misioneros novohispanos de la edad dorada.

Espinosa (1997) recoge las declaraciones de quienes lo conocieron durante su época de formación religiosa en el Convento de la Corona, así transcribe las palabras del R. P. Predicador Fr. Vicente Andàni de la Santa Provincia de Valencia:

Lo que puedo decir con verdad, es, que todo el tiempo, que en los Estudios de Philosophia, y Theologia estuvimos juntos, siempre fue un ejemplar espejo de 
virtudes a Estudiantes, Padres Lectores, â todos los que le conocían, y trataban, como un Varón elegido, y señalado de la mano de Dios desde su niñez para exemplar del Mundo en la inclinación, y anhelo â todo género de virtud: assi en la Pobreza, Obediencia, y Castidad, como en la Humildad, Paciencia, mortificación de gustos, y sentidos: en cilicios, y penitencias: lo que en él era muy frecuente en fervorosa charidad para con Dios y los proximos, y MAXIME enfermos, que se aplicaba con más gusto, y promptitud. Por último, en todas las virtudes se aplicaba a lo más perfecto, y procuraba exercitarse, y caminar continuamente de virtud en virtud, siendo siempre nuestro exemplo, y el primero en acudir todos los actos de Comunidad (p. 27).

Durante sus años de estudio, descolló entre sus compañeros por su disciplina académica y por su entrega a la vida ascética y mística; asimismo, manifestó un constante desprecio por el mundo:

El Padre Francisco Ordaño... le vio tener levantada una de las losas de los sepulcros, y estarse un grandíssimo rato con la cabeza dentro de la sepultura percibiendo toda la hediondez que exhalaba de la horrorosa caverna. Riñéndole sobre esto el Maestro, dixo con rendimiento humilde: "que lo hacía, para que el bruto cuerpo viesse lo que era" (p. 23).

A los veintisiete años entró en contacto con el padre Fr. Antonio Linaz de Jesús María, quien había sido comisionado para la fundación del Colegio de Propaganda Fide de la Santa Cruz en Querétaro; sí, pasa definitivamente a la América septentrional. Se describen sus entradas en los montes de Centroamérica, desde Costa Rica hasta Chiapas, y penetrando en la extensa zona norte de México, en las sierras del Nayar y en los desiertos 
de Nuevo León, Coahuila y Texas. Durante la primera etapa de su labor misional en Mesoamérica viajó en compañía de Fr. Melchor López; mientras que, en la segunda etapa, en el norte, su compañero fue Fr. Isidro Félix de Espinosa, autor de la crónica.

La característica más sobresaliente del misionero es su elocuencia, la cual coincide con la razón principal de la Rhetorica Christiana. Con respecto al uso del sermo humilis que recomendaba Valadés, Espinosa (1997) dice:

Comenzó la tarea del Púlpito, enderezando todos sus sermones al alma con provechosa moral doctrina: pues son sermones sin alma, los que carecen de ella, en sentencia de los Predicadores Santos. Estaba en uso, y aun lo está al presente, como se vee en sermones predicados en aquel Reyno, y testifican Personas fidedignas, el no predicar solo flores de panegyricos discursos, sin insertarse, lo moral, de que redundan frutos en los oyentes: y así el nuevo Predicador desde los principios hizo fructuosos sus sermones. No se afanó por aquellas bizarras galanterías, que alhagando al oído, dexan el corazón árido, ni se valió de aquellas subtilezas, que picando en los entendimientos agudos, no sacan sangre de la voluntad (p. 33). Incluso, como parte del portento que hacía su elocuencia, durante seis años predicó, al parecer sin conocimiento de las lenguas nativas, entre los talamancas, los térrabas, los borucas, donde hace asombrosas conversiones y hasta logra que los propios indígenas le entreguen sus ídolos para ser destruidos:

Absortos escuchaban estas razones aquellos bárbaros: admiraban su constancia intrépida, su eficaz persuasiva, su tolerancia en los trabajos, su duro padecer en la falta de sustento y natural desabrigo, y sobre todo el desapego de todo lo temporal, siendo el desinterés argumento tan convincente que basta persuadir la verdad de lo 
que se dice al tosco entendimiento de un gentil. Llegaron después de largas conferencias a persuadirse ser segura la Ley, que se les proponía, viendo la inculpable vida de quien la promulgaba, y se ofrecieron rendidos aquellos rapaces Lobos a la obediencia, y sujeción de estos dos mansos Corderos, deseando ya libertarse de la tyrania del demonio, y ser adoptados por hijos de Dios con el Santo Bautismo (p. 68).

En la construcción del personaje de Margil, como muestra en la cita anterior, es indispensable la presencia del "otro" indígena. Al igual que en las crónicas del siglo XVI, su figura está estereotipada, asociada con lo demoníaco e idolátrico cuando no está convertido, o con la sumisión total cuando es cristiano.

\subsection{Uso del exemplum para la construcción del "otro" indígena}

Tal y como hizo Fr. Diego Valadés en su aproximación etnológica del “otro", Espinosa utiliza también la forma retórica del exemplum para adentrarse en el mundo del indígena. Al igual que como se anotó para la Rhetorica Christiana, el indio es solo el material humano sobre el cual los frailes ejercen sus virtudes a través del proceso evangelizador y de la cura de almas. Rubial (1999) asevera que:

Los indios son más objeto que sujeto, más escenografía que actor, son, en fin una construcción retórica. Sus vicios son un espejo de la moral cristiana que considera a la idolatría como un mal, por ello los idólatras deberán mostrarse como tiranos, sodomitas, avaros, carniceros (p. 265).

Como en el caso de la Rhetorica Christiana, los indígenas en la obra de Espinosa (1997) se mueven entre el vituperio y la exaltación, de acuerdo con las necesidades e 
intenciones de la narración. Cuando se mencionan los logros de los frailes al reducir a los indios a pueblos, se describen como dóciles y de naturaleza afable; los frailes aprenden las lenguas con los niños y los cuidan como padres. En otras ocasiones, los misioneros establecen lucha campal contra los demonios que a través de los idólatras queman las iglesias recién levantadas, les envenenan la comida y ponen a su paso todo tipo de traspiés. En todo momento, la providencia divina les abre el camino:

Gustosos se ocupaban los dos fervorosos misioneros en el catequismo de aquellos gentiles de la Talamanca, quando algunos idólatras, que apostaban durezas con los diamantes, instigados del príncipe de las tinieblas, que advertía iba ya de caída su tyránico imperio, intentaron por varios modos apagar la luz de aquellas vidas, que como vivas antorchas desterraban las tinieblas de su barbarismo. Enredados en la maleza de sus mesmas confusiones, y depravados intentos, no encontraban modo de reducir a la practica de sus designios; ya sea porque les ataba el Señor las manos, o por el vil temor de los que afectos a los Padres, estaban ya bautizados (p. 71).

Aunque las misiones en Centroamérica eran aparentemente un éxito, en el capítulo XVII, Espinosa hace un acercamiento "etnográfico" al estilo de Valadés. Después de describir la vida en los pueblos indígenas de Costa Rica y de Nicaragua, presenta un informe de un obispo de León en el cual da cuenta del pobre estado de las misiones de la alta Talamanca; la solución que sugiere es hacer bajar a los indios de las montañas para apacentarlos en pueblos. A raíz de esta situación, cosa muy extraña para una crónica de este tipo, Margil justifica una entrada militar en la Lacandonia para abrir una ruta por Campeche. Para esto, se reactiva la vieja discusión del siglo XVI sobre la guerra justa contra los indios. Este pasaje poco ortodoxo, en relación con el estilo retórico que se ha 
presentado, es rápidamente reorganizado por Espinosa, y las campañas militares no son narradas por ningún lado, quizá se debe a un lapsus narratológico del cronista, quien mostró una fisura en este mundo ideal. En el año 1704, debido a sus “exitosas” empresas en el sur, sus superiores lo envían a reactivar las misiones del norte, en la sierra del Nayar. Para 1721, en medio de la guerra entre Francia y España, funda las misiones de San Antonio, Texas.

Tal y como lo presentó en su momento Valadés, en el Nuevo Mundo, ausente por completo de la herejía de los musulmanes y judíos, la idolatría era la manera en que se manifestaba el archi-antagonista de la fe. Asimismo, en la obra de Espinosa, el diablo tiene una función narrativa preponderante. Las luchas contra "las depravaciones demoníacas", Margil las hacía con los instrumentos de fe prescritos por Trento: predicación, apoyada a menudo con una procesión por las calles de los pueblos, azotándose y cargando pesadas cruces; hogueras y autos de fe con los ídolos. Se relata incluso una ocasión en la cual, como Jacob con el ángel, Margil luchó físicamente contra un demonio para arrebatarle una cédula de esclavitud que había firmado un pecador arrepentido. El Demonio no solo se encontraba entre los indios bárbaros, también su presencia había penetrado en las urbes de mestizos y de criollos. Se narra cómo el misionero hacía que los enemigos se reconciliaran, corregía los amancebamientos, la blasfemia, los juegos de azar; se lanzaba contra las representaciones de comedia que consideraba demoníacas, su llegada traía siempre consigo el alivio a las desgracias materiales y espirituales.

La retórica se convertía en el arte de "hacer creer", lograba independizar las palabras de los hechos. Por medio de elementos exteriores a la prédica, se conseguía 
interiorizar la vivencia religiosa, con lo cual se creaba en los fieles la persuasión de que era posible imitar las acciones de Cristo.

\subsection{Algunos elementos de la composición retórica de $E l$ peregrino septentrional atlante a la luz de la Rhetorica Christiana}

Fr. Isidro Félix de Espinosa es el primer criollo que inicia un ciclo hagiográfico sobre un siervo de Dios "novohispano". Espinosa fue compañero misionero de Margil y también desempeñó puestos importantes dentro de la orden. En 1733 fundó un colegio más de Propaganda Fide, la cuarta institución en su estilo, el Colegio de San Fernando de México. Además, fue autor prolífico y sus contemporáneos lo apodaban “Julio César”, pues trabajaba de día y escribía de noche. Se presentan a continuación algunos aspectos de la formación discursiva de su obra.

El peregrino septentrional atlante está dividido en tres libros. Los dos primeros se refieren a los hechos biográficos del fraile. En ellos, se urde la vida de Margil y se usan las formas retóricas tal y como lo recomienda Valadés. Inventio, dispositio y elocutio se acomodan a las necesidades persuasivas del texto. Cabe mencionar la importante influencia que las crónicas de viaje, tan en boga en el momento, suponen para gran parte de la dispositio que narra las itinerancias del fraile; también, el uso de la forma del exemplum (ya mencionado) lo es para las apreciaciones "etnológicas" de la vida de los indígenas. Por supuesto, en el texto abundan las figuras retóricas, tropos, citas de autoridades tanto religiosas como paganas, citas de la Sagrada Escritura e incluso de fuentes mitológicas.

El libro tercero se diferencia de los anteriores. En este, se aborda por completo la figura del predicador para presentar un modelo a emular. Los veintidós capítulos 
contenidos en este son una lección para los frailes en el cumplimiento de sus votos y virtudes. Aunque repetitiva, esta parte del libro es un verdadero tratado teológico lleno de juegos retóricos.

El tema central gira en torno al tópico clásico de la fama, la muerte trascendida por las obras. En este libro se insertan los sermones fúnebres que se dijeron en honor de Margil, se incluyen algunas cartas y escritos del venerable padre que muestran su virtud y su ciencia. Sus virtudes se expresan con las metáforas tomadas de los tratados clásicos de emblemática y de los lapidarios medievales:

Como entre los elementos se lleva la primacía el Fuego, entre los metales el Oro, entre los cielos el Empireo, y entre los Coros de los Ángeles son los Serafines los más sublimes, assi entre las virtudes la Charidad es el fuego, que enciende los corazones, el oro con que compramos el Cielo, el Empireo en que habita el mesmo Dios, y la que transforma los hombres en alados Serafines. Los incendios de la Charidad del Serafin en carne Fr. Antonio se dan a conocer por sus vuelos (Espinosa, 1997, p. 342).

El libro tercero es el que se podría considerar más hagiográfico de la crónica. Aunque en los dos primeros se encuentran portentos como conocer las conciencias, el don de la ubicuidad, la sorprendente velocidad con que recorría largas distancias y la levitación; después de muerto, sus portentos parecen multiplicarse por toda Nueva España. Según Rubial (1999), con la llegada de su muerte se marca una línea divisoria con lo maravilloso, y este se manifiesta de manera exuberante. Así, el relato de su traslado de Querétaro a México, ya en tránsito de muerte, es una suma de milagros, curaciones físicas y visiones. Una vez muerto, los milagros se suceden alrededor de su cuerpo insepulto al contacto con 
sus pertenencias, sin importar la ubicación geográfica de estas; así llegan noticias de milagros en Guatemala por una carta de su puño y letra o por un sayón viejo, ahora reliquia de fe en el norte. En algunos momentos, el cronista debe forzar su retórica y se ve en la necesidad de justificar los pasajes que contradicen las limitaciones impuestas por Urbano VIII, en su bula de 1625, sobre la escritura de hagiografías de personas no canonizadas.

\section{Conclusiones}

Como se ha demostrado, El peregrino septentrional atlante es una de las últimas crónicas escritas en Nueva España, heredera de un estilo cuya preceptiva cifró Fr. Diego Valadés en su Rhetorica Christiana. También es heredera de un arquetipo de misionero forjado en el Nuevo Mundo y cuya figura bien pulida es Margil.

Ambos documentos aportan información importante al estudioso contemporáneo sobre el proceso de colonización y aculturación de los habitantes del virreinato. La formación retórica del indio como ser binario, se concibe en la "edad dorada" de la evangelización y se mantiene idéntica todavía en el siglo XVIII. En ambos documentos, por supuesto, están ausentes los séquitos de indios cargadores, intérpretes y guías que mostraban los mejores caminos y facilitaban el contacto con los pueblos aborígenes, así como las rudas penitencias físicas impuestas a los indios insumisos por los mismos frailes.

Finalmente, El peregrino septentrional atlante es un texto limítrofe en tres dimensiones:

- $\quad$ Espacialmente: Las jornadas misioneras de Margil se llevan a cabo en los extremos de Nueva España: Texas y Centroamérica, zonas aún agrestes que permitían revivir la edad dorada. 
- Temporalmente: La crónica muestra ciertas características híbridas con respecto a la preceptiva barroca; por ejemplo, frente a la idea idílica de la reavivación de la edad dorada de la evangelización aparecen constantes fracasos misionales o la presencia de actos prodigiosos mezclados con labor misionera y obra apostólica.

- $\quad$ Preceptiva barroca: Este es un ejemplo de los últimos textos hagiográficos cuya formación narrativa es de raíz tridentina.

\section{Referencias}

Carrasco, R. (2000). El exemplum como estrategia persuasiva en la Rhetorica cristiana (1579) de fray Diego Valadés. Revista Anales del Instituto de Investigaciones Estéticas, $\quad$ XXII(77), 33-66. http://dx.doi.org/10.22201/iie.18703062e.2000.77.1939

Espinosa, I. F. (1997). El peregrino septentrional atlante. Delineado en la exemplarissima vida del venerable padre F. Antonio Margil de Jesús. (1. ${ }^{\text {r }}$ reimp.). Querétaro, México: Talleres gráficos de Gobierno de Estado.

Rubial García, A. (1999). La santidad controvertida. México: FCE.

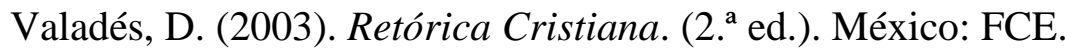

Vernier, M. E. (2001). La Rhetorica Cristiana de Diego Valadés. Caravelle. Cahiers du monde hispanique et luso-brésilien (76-77), 437-442. https://doi.org/10.3406/carav.2001.1321 